\title{
MOEGLIN, Jean-Marie, MÜLLER, Rainer A., Deutsche Geschichte in Quellen und Darstellung. Band 2 : Spätmittelalter 1250-1495
}

Pierre Monnet

\section{OpenEdition}

Journals

Édition électronique

URL : http://journals.openedition.org/ifha/1299

DOI : 10.4000/ifha.1299

ISSN : 2198-8943

Éditeur

IFRA - Institut franco-allemand (sciences historiques et sociales)

Référence électronique

Pierre Monnet, « MOEGLIN, Jean-Marie, MÜLLER, Rainer A., Deutsche Geschichte in Quellen und Darstellung. Band 2: Spätmittelalter 1250-1495», Revue de l'IFHA [En ligne], Date de recension, mis en ligne le 01 janvier 2000, consulté le 22 septembre 2020. URL : http://journals.openedition.org/ifha/ 1299 ; DOI : https://doi.org/10.4000/ifha.1299

Ce document a été généré automatiquement le 22 septembre 2020

(CIFHA 


\title{
MOEGLIN, Jean-Marie, MÜLLER, Rainer A., Deutsche Geschichte in Quellen und Darstellung. Band 2: Spätmittelalter 1250-1495
}

\author{
Pierre Monnet
}

La parution de recueils de textes et de documents à la fois scientifiquement édités, disponibles en un format accessible et peu coûteux, et destinés au public universitaire n'est pas si fréquente en Allemagne. C'est pourquoi la collection « Deutsche Geschichte in Quellen und Darstellung " mérite à plus d'un titre d'être signalée. Elle vient de s'enrichir d'un volume couvrant l'histoire allemande de la fin du Moyen Âge, complétant ainsi le volume publié en 1995 par les soins de Wilfried Hartmann pour la période 750-1250. Comme les onze autres volumes de la série (désormais au complet), celui-ci se présente sous la forme d'un recueil de textes ordonnés suivant la chronologie «classique » qui voit l'Empire médiéval passer de l'Interrègne consécutif à la mort de Frédéric II, le dernier Staufen, en 1250, à la réforme des institutions marquées par la création en 1495 du Reichskammergericht. Après une introduction synthétique qui fait le point sur les grands problèmes que traverse l'Empire des principautés aux trois siècles finaux du Moyen Âge (la dualité Empire/empereur, les grands traits de la politique royale, le passage de la souveraineté princière à l'État territorial, la réforme de l'Empire), le lecteur et l'étudiant trouveront là les grands textes (donnés en traduction suivant les grandes éditions des Monumenta, des Geschichtschreiber der deutschen Vorzeit ou bien de la Quellensammlung zur Geschichte der deutschen Reichsverfassung im Mittelalter und Neuzeit et de la Quellensammlung zur Verfassungsgeschichte des Römisch-Deutschen Reiches im Spätmittelalter) permettant de comprendre la complexité du jeu à quatre (roiempereur, pape, princes, villes) qui explique en grande partie l'évolution ultérieure de l'Empire de la Réforme à 1806. On notera, dans le choix opéré par les deux éditeurs, la très grande attention portée à la variété des types de sources retenues : constitutions, décrets, ordonnances, traités politiques, miroirs, chroniques, protocoles urbains, 
recueils de droits... Des cartes, des illustrations, des sceaux et des plans viennent compléter la documentation. Chaque texte est accompagné de la mention des éditions latine et allemande ainsi que d'une introduction critique fournissant les éléments principaux de commentaire. Il est à peine besoin de dire que ce petit volume devra désormais figurer dans la bibliothèque de tout étudiant et chercheur en histoire de l'Empire.

Pierre MONNET 